\title{
Review: haloperidol decanoate is superior to placebo for schizophrenia
}

\author{
Quraishi S, David A. Depot haloperidol decanoate for schizophrenia. (Cochrane Review, latest version 25 Nov 1998). In: Cochrane \\ Library. Oxford: Update Software.
}

\section{Question}

In patients with schizophrenia, is haloperidol decanoate effective compared with oral antipsychotics and other depot antipsychotics?

\section{Data sources}

Studies were identified using 7 electronic databases; references of relevant studies were scanned; authors were contacted; and requests were made to companies that produce depot injections of antipsychotics.

\section{Study selection}

Studies were selected if they were randomised controlled trials that compared depot haloperidol decanoate with placebo, oral antipsychotic drugs, or other depot antipsychotic drugs.

\section{Data extraction}

Data were extracted on patient characteristics and follow up, setting, intervention, outcome measures, and methodological quality. Outcomes included measures of global impression and mental state.

\section{Main results}

11 studies met inclusion criteria. 2 studies (88 patients) compared haloperidol decanoate with placebo. A substantial number of patients did not complete the studies (40\%) but fewer patients receiving haloperidol withdrew than did those receiving placebo (14\% v 76\%). 1 study (32 patients) showed that patients taking haloperidol required less of other types of antipsychotic medication $\{\mathrm{p}=0.004\}^{*}$; and also showed that haloperidol recipients had a greater improvement in mental state $\{\mathrm{p}<0.001\}^{*}$ (table). 1 study (22 patients) compared haloperidol decanoate with oral haloperidol and showed no difference for improvement on the Clinical Global Impression (CGI) scale or for change in mental state using the Brief Psychiatric Rating
Scale (BPRS). 8 studies (371 patients) compared haloperidol decanoate with other depot antipsychotics. No differences between groups were seen for requiring additional antipsychotic medication (2 studies) $\{\mathrm{p}=0.48\}^{*}$ (table), endpoint on the CGI scale (2 studies) (95\% CI for the 0.07 weighted mean difference in CGI score -0.2 to 0.4 ), relapse (7 studies) $\{\mathrm{p}=0.52)\}^{*}$ (table), BPRS endpoint score (2 studies) (CI for the 0.87 weighted mean difference in BPRS score -1.0 to 2.7$)$, or leaving the study early (8 studies) $\{\mathrm{p}=0.074\}^{*}$.

\section{Conclusions}

Data comparing haloperidol decanoate with placebo or oral haloperidol are sparse. Trials comparing haloperidol decanoate with other oral and depot antipsychotics show no differences in global impression or mental state.

*p values calculated from data in article.

Haloperidol decanoate $(H D)$ v placebo and other depot neuroleptics $(O D)$ for schizophreniat

\begin{tabular}{|c|c|c|c|c|}
\hline Outcomes & Comparison & Event rates & $R R R(95 \% C I)$ & $N N T(C I)$ \\
\hline \multirow{3}{*}{$\begin{array}{l}\text { Global impression } \\
\text { Need for additional } \\
\text { antipsychotic } \\
\text { medication }\end{array}$} & & & & \\
\hline & $\begin{array}{l}\text { HD v } \\
\text { placebo }\end{array}$ & $31 \%$ ข $81 \%$ & $\begin{array}{l}62 \% \\
(25 \text { to } 83)\end{array}$ & $2(1$ to 6$)$ \\
\hline & $\mathrm{HD} v \mathrm{OD} \ddagger$ & $\begin{array}{l}7.2 \% v \\
10.7 \%\end{array}$ & $\begin{array}{l}35 \% \\
(-81 \text { to } 117)\end{array}$ & $\begin{array}{l}\text { Not } \\
\text { significant }\end{array}$ \\
\hline $\begin{array}{l}\text { Mental state } \\
\text { No discernible } \\
\text { effect }\end{array}$ & $\begin{array}{l}\mathrm{HD} v \\
\text { placebo }\end{array}$ & $0 \%$ v $81 \%$ & $\begin{array}{l}100 \% \\
\text { (76 to } 100)\end{array}$ & 1 (1 to 2$)$ \\
\hline Outcome & Comparison & Event rates & $R R I(95 \% C I)$ & $N N H$ \\
\hline Relapse & $\mathrm{HD} v \mathrm{OD} \ddagger$ & $\begin{array}{l}14.5 \% v \\
14.2 \%\end{array}$ & $\begin{array}{l}17 \% \\
(-15 \text { to } 27)\end{array}$ & $\begin{array}{l}\text { Not } \\
\text { significant }\end{array}$ \\
\hline
\end{tabular}

†Abbreviations defined in glossary; RRR, RRI, NNT, NNH, and CI calculated from data in article. $\ddagger$ Event rates are weighted.

Source of funding:NHS-REDD Health Technology Assessment Programme.

For correspondence: Ms S Quraishi, Department of Psychological Medicine, King's College School of Medicine and Dentistry, 103 Denmark Hill, London SE5 8AF, UK. Fax +44 (0)171 7405129.

\section{Commentary}

This is the second meta-analysis of depot antipsychotics. The first concerned fluphenazine decanoate and came to similar conclusions. ${ }^{1}$ Long acting neuroleptics are widely prescribed, especially for patients who are at high risk of noncompliance with oral treatment. ${ }^{2}$ No sound evidence exists that depot neuroleptics are more effective than oral treatment when part of a comprehensive psychosocial programme for patients with severe mental disorders. When given as the only treatment, parenteral neuroleptics may be superior to oral treatment. This would be considered an unacceptable level of care, however, in most developed countries. Patients with a high risk of violent behaviour would be those for whom a guaranteed drug treatment is most important. In most countries, no laws permit involuntary outpatient treatment, which might be the only way to achieve successful treatment of those most in need.

In patients with a refractory psychosis, parenteral treatment adds no benefit except for the few with intestinal disorders that interfere with drug absorption. Treatment with clozapine, the only effective drug in many patients not responding to or tolerating conventional antipsychotics, must have patient cooperation because it can only be given orally and requires regular blood monitoring.

The current emphasis on patients' rights and respect for patients' choices also holds for patients with chronic psychoses. To arrive at a treatment plan, the type of drug, dosage, and administration route must be negotiated with the patient. In many cases this is a continuous process, with renegotiations becoming part of the ongoing therapeutic relationship. The results of these negotiations may be a decision to use long acting neuroleptics.

Personal participation in 1 of the included studies in this review makes me doubt the feasibility of a large study comparing oral and depot neuroleptics in those patients who have the most to gain from such a study.

Sten Thelander, MD The Swedish Council on Technology Assessment in Health Care Stockholm, Sweden

1 Adams C, Eisenbruch M. Cochrane review, latest version 27 Aug 1997. In: Cochrane Library. Oxford: Update Software.

2 Barnes TR, Curson DA. Drug Saf 1994;10:46479. 